【論文】

\title{
結晶転移により蓄熱する蓄熱材に及ぼす劣化の影響 Influence of Degradation on Storage of Heat of Heat Storage Material with Crystal Transformation
}

\author{
國拓也* 戸谷剛 $* * \quad$ 佐藤敏文** 磯野拓也** \\ 脇田督司** 永田晴紀** \\ Takuya KUNI, Tsuyoshi TOTANI, Toshifumi SATOH, Takuya ISONO, \\ Masashi WAKITA, and Harunori NAGATA
}

\begin{abstract}
本研究では超小型人工衛星用蓄熱材料として, 結晶転移によって蓄熱を行うトランス-1,4-ポリブタ ジェン（TPBD）に注目した. 同一のサンプルに対して蓄熱量の測定および分子構造の測定を行った. 測定結果から, TPBD の分子構造内の- $\mathrm{CH}_{2}$ の自動酸化による $\mathrm{C}-\mathrm{H}$ 結合の変化が，蓄熱量に影響を与え ていることが確認できた，連続使用の中での蓄熱量の変化を確認するために熱サイクル試験を行った。 熱サイクル試験によって得られた温度履歴から蓄熱量及び放熱量の算出を行った結果, 蓄熱量は 60 $\mathrm{J} / \mathrm{g}$ から $90 \mathrm{~J} / \mathrm{g}$ の間に, 放熱量は-65 J/g から-100 J/g の間になることが分った．静止軌道衛星約 4 年半 の運用期間に相当する 1700 回の蓄熱および放熱では蓄熱量の熱サイクル劣化は確認できなかった.
\end{abstract}

Trans-1,4-Polybutadiene (TPBD) transforms a crystal structure at the temperature of heat storage. In this study, the molecular structure of TPBD was measured using the Raman spectroscopy. The measurement of the amount of heat storage of TPBD was performed using a differential scanning calorimetry. It is found that there is a correlation between the amount of heat storage and the change of $\mathrm{C}-\mathrm{H}$ bond by auto-oxidation. A thermal cycle test was carried out to obtain the change of heat storage and release amount of TPBD. The heat storage and release amount was calculated from the obtained temperature history. The heat storage amount became between $60 \mathrm{~J} / \mathrm{g}$ and $90 \mathrm{~J} / \mathrm{g}$. The heat release amount became between $-70 \mathrm{~J} / \mathrm{g}$ and $-100 \mathrm{~J} / \mathrm{g}$. It is verified that the amount of heat storage of TPBD does not deteriorate during 1700 cycles.

[Keywords: Degradation, Heat storage material, Polymer, Auto-oxidation, Satellite]

\section{1. 緒言}

超小型人工衛星は, 熱容量が小さく温度変動が激しい という特徴や，地上とのデータ送信で通信器に急激な温 度上昇が発生するという特徵を持つ。このような急激な 温度上昇や, 激しい温度変動から機器を守るため, 超小型 人工衛星への蓄熱材料の導入が注目されている.

宇宙機用の蓄熱材としては，パラフィンやアルコール などの有機化合物や, $\mathrm{Na}_{2} \mathrm{SO}_{4} \cdot 10 \mathrm{H}_{2} \mathrm{O}$ などの無機水和塩や 水などの無機元素が使われてきた[1].これらの蓄熱材は 固体から液体への相変化により蓄熱するため, 蓄熱材と

* 北海道大学 大学院工学院, $\overline{\bar{T} 060-8628 ~}$ 北海道札幌市北区 北 13 条西 8 丁目

Graduate School of Engineering, Hokkaido University, Kita 13 Nishi 8, Kita-ku, Sapporo, Hokkaido, 060-8628.

E-mail: t-kuni@frontier.hokudai.ac.jp

** 北海道大学 大学院工学研究院, $\bar{\top} 060-8628$ 北海道札幌市 北区北 13 条西 8 丁目.

Faculty of Engineering, Hokkaido University, Kita 13 Nishi 8, Kita-ku, Sapporo, Hokkaido, 060-8628.

E-mail: tota@eng.hokudai.ac.jp
容器との間の濡孔性の考慮と専用の容器を必要とする.

超小型人工衛星用の蓄熱材料としてトランス-1,4-ポリ ブタジェン（TPBD）に注目している．TPBD は低温相か ら高温相への結晶転移によって蓄熱を行う有機高分子材 料である. 液体一の相変化を行わないため, 濡れ性の考慮 や専用の容器を必要としないという宇宙空間での使用に 適した特徴を有している. 著者らは, TPBD を超小型衛星 ほどよし 4 号機に搭載し,宇宙実証試験を行っている[2].

TPBD の分子構造を図 1 に示寸. 天然ゴムなどに代表さ れる- $\mathrm{CH}_{2}$ を有している有機高分子は，熱や光などのエネ ルギーを受けると- $\mathrm{CH}_{2}$ 内の $\mathrm{C}-\mathrm{H}$ 結合が高いエネルギー状 態へ励起され, 空気中の酸素によって化学結合の一部が 変化する自動酸化と呼ばれる現象によって劣化が進行す ることが知られている[3]. 結晶性高分子である TPBD の 結晶化度は立体規則性および分子量に依存している[4]. 化学結合が変化し, 分子量に変化が生じると結晶化度に 変化が生じ, 結晶転移温度や蓄熱量などに影響を及ぼす ことが予測される. 図 1 に示寸通り, TPBD も分子構造内 
に- $\mathrm{CH}_{2}$ を有していることから，自動酸化による劣化が発 生することが予想される. しかし, 自動酸化によって生じ る分子構造の変化が蓄熱性能一与える影響は明らかにな っていない. 超小型人工衛星への搭載を想定した場合, TPBD は数万回の蓄熱および放熱を繰り返す必要がある. 超小型人工衛星の蓄熱材料としての実用化のためには長 期間の蓄熱・放熱の繰り返しの中での蓄熱量および放熱 量の劣化特性に関して検証を行う必要がある.

本研究では, ラマン分光法を用いて TPBD の分子構造 の状態を明らかにし, 熱分析の手法として示差走查熱量 測定（DSC）を用いて蓄熱量の測定を行うことで，TPBD の分子構造の変化と蓄熱量の関係性の調查を行うことを 第 1 の目的とする.また, 地上での対照実験として熱サイ クル試験によって繰り返し加熱・冷却を行い, 連続使用の 中での蓄熱量の変化の調查を第 2 の目的とする.

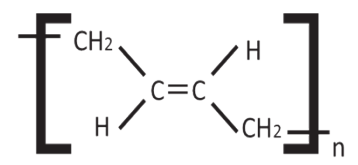

Fig. 1 Chemical structure of Trans-1,4-Polybutadiene

\section{2. 実験概要}

\section{1 トランス-1,4-ポリブタジエン}

TPBD は, ブタジエン $\left(\mathrm{CH}_{2}=\mathrm{CH}-\mathrm{CH}=\mathrm{CH}_{2}\right)$ の付加重合 によって合成することができ[5], 表 1 に示寸物性值を有 している．比熱はホットディスク法熱物性測定装置

(Kyoto Electronics Manufacturing Co., Ltd., Thermal Measuring Instrument TPS2500S）を用いて測定を行った。

Table 1 Physical properties of Trans-1,4Polybutadiene[5][6][7]

\begin{tabular}{ll}
\hline Density & $706 \mathrm{~kg} / \mathrm{m}^{3}$ \\
Specific heat $\left(20{ }^{\circ} \mathrm{C}\right)$ & $1.57 \mathrm{~kJ} /(\mathrm{kg} \cdot \mathrm{K})$ \\
Latent heat & $69-124 \mathrm{~kJ} / \mathrm{kg}$ \\
Transition point & $50-80 \mathrm{deg} \mathrm{C}$ \\
\hline
\end{tabular}

\section{2 蓄熱量の測定}

蓄熱量および放熱量の測定は，示差走查熱量測定装置

（METTLER TOLEDO, DSC1）を用いた. 本実験では研 究室において保管していた TPBDから, RD01，RD02 お よびRD03 の 3 つのサンプルを取り出し測定を行った. TPBM は，ビニール袋に入れられ，室温で，太陽光が当
たる場所に保管されていた． 3 つのサンプルはそれぞれ， ビニール袋内の異なる位置から採取された。測定温度範 囲は，参考文献[7]より，低温側は結晶転移温度である 50 $\operatorname{deg} \mathrm{C}$ 近傍から十分離れた温度である $20 \operatorname{deg} \mathrm{C}$ と, 高温 側は融点である $130 \operatorname{deg} \mathrm{C}$ 近傍から十分離れた $90 \operatorname{deg} \mathrm{C}$ と した。本実験における実験条件を表 2 に示す。

Table 2 Measurement conditions of DSC

\begin{tabular}{ll}
\hline Temperature range & $20-90 \operatorname{deg} \mathrm{C}$ \\
Sample Pan & Aluminum $40 \mu \mathrm{l}$ \\
Atmosphere & $\mathrm{N}_{2}$ \\
Flow rate of $\mathrm{N}_{2}$ & $30 \mathrm{ml} / \mathrm{min}$. \\
Heating / cooling rate & $2 \mathrm{deg} \mathrm{C} / \mathrm{min}$. \\
\hline
\end{tabular}

測定時の加熱および冷却条件は以下の通りである.

$1: 10 \mathrm{~min}$ 間材料を $20 \mathrm{deg} \mathrm{C}$ で保持

$2:+2 \mathrm{deg} \mathrm{C} / \mathrm{min}$ で昇温

3: $10 \mathrm{~min}$ 間材料を $90 \mathrm{deg} \mathrm{C}$ で保持

$4:-2 \operatorname{deg} \mathrm{C} / \mathrm{min}$ で泠却

DSC 測定では, 昇温速度が大きいと, 蓄熱温度は高温側 にシフトし, 降温速度を大きいと, 放熱温度は低温側にシ フトする. DSC 装置はサンプルを入れる容器の外側の底 部で温度を測定していて, 熱は容器の外側から容器を通 して, サンプルに熱伝導で伝わるため, 容器外側の底部と サンプルの温度変化に差が生じ，上記のシフトが発生す ることが知られている. 参考文献[5]では, 昇温降温速度 $10 \mathrm{deg} \mathrm{C} / \mathrm{min}$ で測定されているが，より正確に蓄・放熱 温度を取得するために, $2 \mathrm{deg} \mathrm{C} / \mathrm{min}$ で測定を行った。

\section{3 分子構造の測定}

本研究ではラマン分光法を用いて TPBD の分子構造の 測定を行った. 測定には, 顕微ラマンマイクロスコープシ ステム（Renishaw, in Via Reflex）を使用した。励起レー ザーとしてNIR laser(Renishaw, HPNIR785, 波長 785 nm) を用い，蓄熱量の測定を行ったサンプルに対して表 3 に 示す測定条件にて測定を行った.

Table 3 Conditions of Raman spectroscopy

$\begin{array}{ll}\text { Laser wavelength } & 785 \mathrm{~nm} \\ \text { Laser power } & 100 \% \\ \text { Object lens magnification } & \times 50 \\ \text { Laser exposure time } & 1 \mathrm{sec} \\ \text { Raman shift resolution } & 1.5 \mathrm{~cm}^{-1}\end{array}$




\section{4 熱サイクル試験}

超小型人工衛星での使用を想定し，熱サイクル試験を 環境試験装置（THERMOTRON, S-8200）を用いて大気 雰囲気下で行った. TPBD サンプルおよび Reference の加熱と冷却は以下に示すサイクルにて連続して与えた.

$1: 20 \operatorname{deg} \mathrm{C} \sim 100 \operatorname{deg} \mathrm{C} \sim 10 \operatorname{deg} \mathrm{C} / \mathrm{min}$. で加熱

2: $100 \operatorname{deg} \mathrm{C}$ で $15 \mathrm{~min}$ 保持

3 : $100 \operatorname{deg} \mathrm{C} \sim 20 \operatorname{deg} \mathrm{C} \sim-10 \operatorname{deg} \mathrm{C} / \mathrm{min}$. で冷却

$4: 20 \operatorname{deg} \mathrm{C}$ で $15 \min$ 保持

TPBD の蓄熱効果を確認するため, アルミテープを用いて TPBD 一白金抵抗温度センサ（CHINO, R060-33）を貼り 付け, 温度計測を行った（図 2 左）。同型の温度センサに アルミテープのみを貼り付け（図 2 右）TPBD の有無によ る温度の違いを比較した. TPBD サンプルのサイズは, 10 $\mathrm{mm} \times 21 \mathrm{~mm} \times 1.5 \mathrm{~mm}$ である. 図 2 では, 撮影のため TPBD が見えるようにアルミテープの一部を剥がしている.

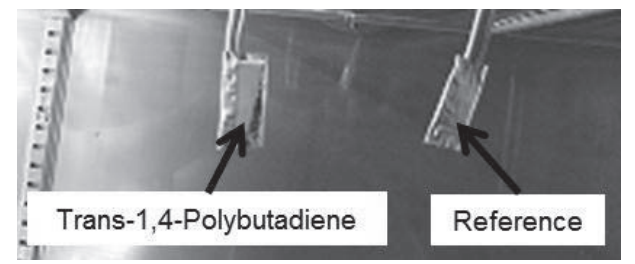

Fig. 2 Setting of the test pieces in a thermal cycle test

\section{3. 測定結果および考察}

\section{1 ラマンスペクトルと蓄熱性能の関係性}

示差走査熱量測定によって得られた 3 つのサンプルの DSC カーブを図 3 に示す. サンプルへの入熱量および出 熱量にピークがあることからサンプルが蓄熱および放熱 を行っていることが確認できる，蓄熱時および放熱時の DSC カーブのピーク高さを比較するとRD01, RD02, RD03 の順に蓄熱量および放熱量が減少していることが確認で きる. DSC カーブから得られた各サンプルの蓄熱量およ び放熱量を，表 4 および表 5 に示す. 3 つのサンプルの DSC カーブのそれぞれで, 蓄熱温度と放熱温度のピーク がずれている. 昇・降温速度を 2～20 deg C/min で変化さ せても, 図 3 と同じ幅のずれは観測できなかったので, 過 冷却現象によるずれであると推測している.

RD01，RD02 およびRD03 のラマンスペクトルを図 4-6 に示す. 図 4 に示す RD01 のラマンシフトにおいて 2899 cm-1，2918 cm-1 および 2945 cm-1 のラマンシフトにおけ るピークが確認できた．これらのピークは-CH2 内の C-H 結合のピーク位置であることが知られている[8]. RD02の

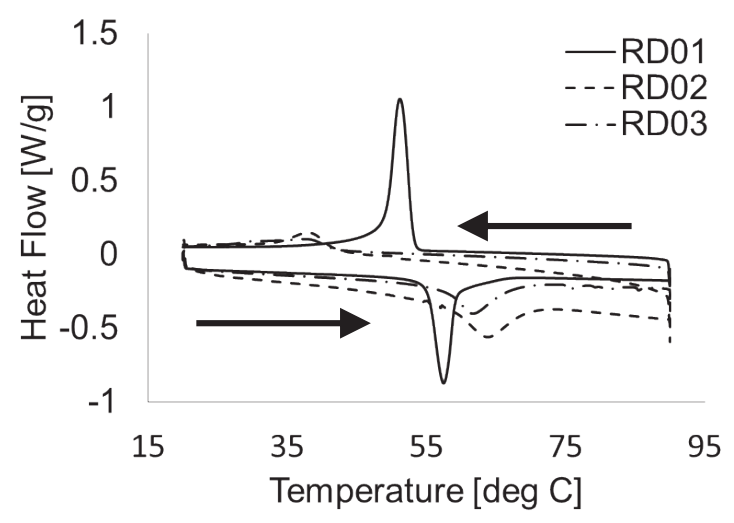

Fig. 3 Comparison of DSC curves

Table 4 Transition temperature and endoergic heat Sample name Transition temperature Endoergic heat

\begin{tabular}{lll} 
RD01 & $7.53 \operatorname{deg} C$ & $73.33 \mathrm{~J} / \mathrm{g}$ \\
$\mathrm{RD} 02$ & $3.77 \operatorname{deg} \mathrm{C}$ & $61.89 \mathrm{~J} / \mathrm{g}$ \\
$\mathrm{RD} 03$ & $1.63 \operatorname{deg} \mathrm{C}$ & $48.96 \mathrm{~J} / \mathrm{g}$ \\
\hline
\end{tabular}

Table 5 Transition temperature and exoergic heat Sample name Transition temperature Exoergic heat

\begin{tabular}{llr} 
RD01 & $1.13 \operatorname{deg} C$ & $104.44 \mathrm{~J} / \mathrm{g}$ \\
RD02 & $8.07 \operatorname{deg} \mathrm{C}$ & $38.49 \mathrm{~J} / \mathrm{g}$ \\
RD03 & $7.63 \operatorname{deg} \mathrm{C}$ & $27.49 \mathrm{~J} / \mathrm{g}$ \\
\hline
\end{tabular}

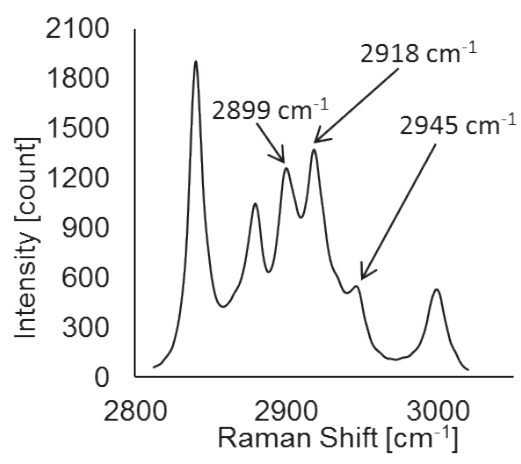

Fig. 4 Raman Spectrum of RD01

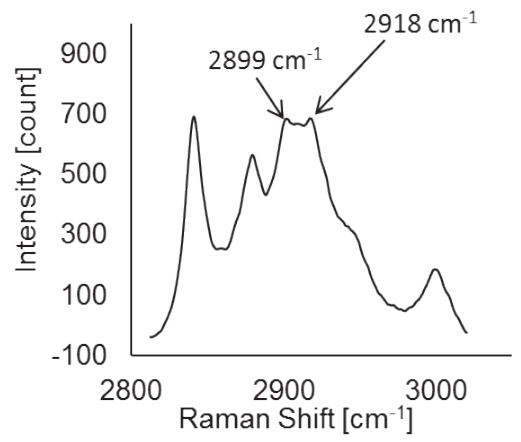

Fig. 5 Raman Spectrum of RD02 


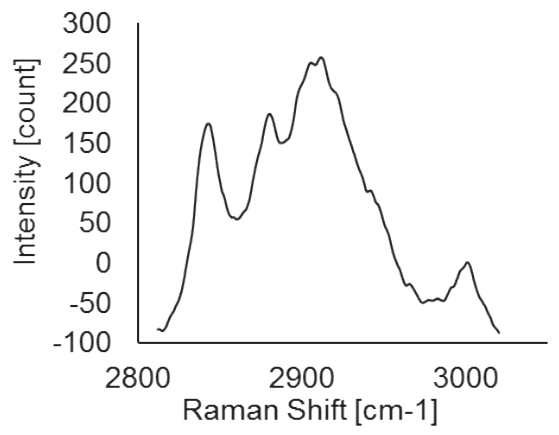

Fig. 6 Raman Spectrum of RD03

ラマンスペクトル（図 5) では, 図4 において確認できた ラマンシフト $2945 \mathrm{~cm}^{-1}$ のピークが確認できず, $2918 \mathrm{~cm}^{-1}$ および $2899 \mathrm{~cm}^{-1}$ のピークが不明瞭なものとなった. 更に, RD03 のラマンスペクトル (図 6)では, RD01 およびRD02 で確認された C-H 結合に関するピークが確認できなかっ た．以上のことから 3 つのサンプル間において C-H 結合 に関する分子構造に違いがあることが確認できた，各サ ンプルは保管時のビニール袋の異なる位置から採取され ており，自動酸化は光に起因して起こることから，RD01 は光が当たりにくく自動酸化が少ないビニール袋の中心 部から, RD03 は最も光が当たりやすく自動酸化が起こり やすいビニール袋付近から採取されたと推測している.

各サンプルの蓄熱量および放熱量と, ラマンスペクトル によって得られた C-H 結合の変化との比較から，自動酸 化による C-H 結合の変化が蓄熱量の劣化に対して影響を 与えていると言える. この結果から, 超小型人工衛星へ卜 ランス-1,4-ポリブタジエンを搭載する際は, 衛星の組み立 て時にトランス-1,4-ポリブタジエンを搭載した後, 打ち上 げまでの間に地上での劣化を防ぐために冷暗所での保管 を行うなどの対応が必要であると言える。

図 3 では，3つのサンプルの蓄熱および放熱時のピー クの位置がずれている. 劣化が原因と推測しているが, ラ マンスペクトルで確認された分子構造の変化とピーク位 置のずれの関係については，十分な知見を有していない.

\section{2 連続使用における蓄熱量の劣化特性}

熱サイクル試験によって得られた TPBD および Reference の温度履歴を図 7 に示寸. 図 7 は 1700 サイクル 目の温度履歴を示している. これらの温度履歴は 1 回目 の温度履歴とほぼ同じである. 昇温時は $65 \mathrm{deg} \mathrm{C}$ 付近か ら $73 \operatorname{deg} C$ 付近で Reference と TPBD の温度の差が増大し ていることから TPBD が蓄熱を行っていることが，冷却

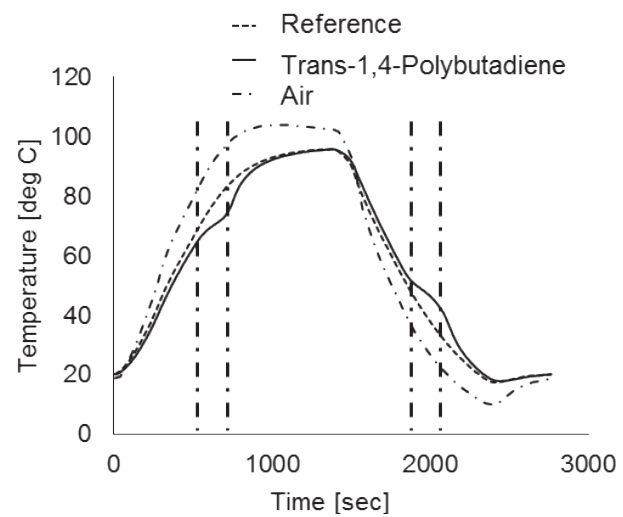

Fig. 7 Temperature history of the thermal cycle test (1700cycle)

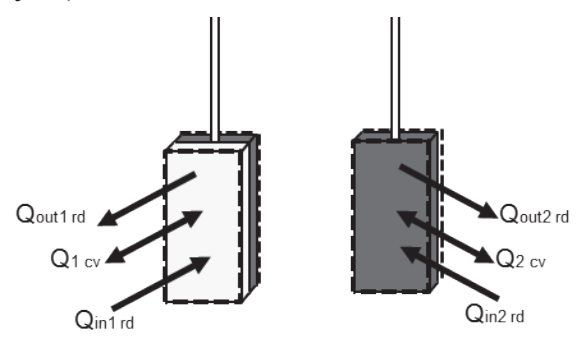

Heat storage device Reference

Fig. 8 Thermal cycle test model

時は $53 \operatorname{deg}$ C 付近から $44 \operatorname{deg}$ C 付近で Reference と TPBD の温度の差が増大していることから TPBD が放熱を行っ ていることが確認できる.

熱サイクル試験における TPBD の蓄熱および放熱量を 図 8 に示寸モデル化を行い，見積もった．TPBD，白金抵 抗温度センサおよびアルミテープによって構成される蓄 熱器および白金抵抗温度センサおよびアルミテープによ って構成される Reference の熱のやり取りは, 図 8 に示す 破線で囲まれた面で行われるとする.

蓄熱器の内部エネルギーの変化, 入熱および放熱の関 係は式（1）と表すことができる，また，Reference の内部 エネルギーの変化, 入熱および放熱の関係は式 (2) と表 すことができる.

$$
\begin{aligned}
& d U_{1}+L=Q_{\text {in } 1}-Q_{\text {out } 1} \\
& d U_{2}=Q_{\text {in } 2}-Q_{\text {out } 2}
\end{aligned}
$$

蓄熱器への入熱および出熱は, 破線にて囲まれた面への 対流熱伝達および固定に使用したアルミテープ表面およ びチャンバー内壁のふく射によって行われるものとし， 
式（3）および式（4）と表すことができる.

$$
\begin{aligned}
& Q_{\text {in } 1}-Q_{\text {out } 1}=Q_{c v 1}+Q_{\text {in } r d 1}-Q_{\text {out } r d 1} \\
& Q_{\text {in } 2}-Q_{\text {out } 2}=Q_{c v 2}+Q_{\text {in } r d 2}-Q_{\text {out } r d 2}
\end{aligned}
$$

ふく射による蓄熱器および Reference への入熱は, 蓄熱器 およびReference の大きさに対して十分に広いチャンバー 内壁からのふく射とし式（5）とする.

$$
Q_{\text {in rd1 }}=Q_{\text {in rd 2 }}
$$

式（1）から式（5）より結晶転移時の潜熱 $L$ に関して整理 すると式（6）と表せる.

$$
\mathrm{L}=d U_{2}+Q_{\text {out } r d 2}-Q_{c v 2}+Q_{c v 1}-\mathrm{d} U_{1}-Q_{\text {out } r d 1}(6)
$$

TPBD および Reference の内部エネルギーの変化 $d U_{1}$ およ び $d U_{2}$ を式（7）および式（8）に示す.

$$
\begin{aligned}
& d U_{1}=d T_{1}\left(m_{A l 1} c_{A l}+m_{p t} c_{p t}+m_{H S T} c_{H S T}\right) \\
& d U_{2}=d T_{2}\left(m_{A l 2} c_{A l}+m_{p t} c_{p t}\right)
\end{aligned}
$$

蓄熱器およびReference を覆っているアルミテープ表面か らのサンプリング周期ごとのふく射による放熱量 Q out rd 1 および Q out rd 2 を式（9）および式（10）に示す.

$$
\begin{aligned}
& Q_{\text {outrd } 1}=\varepsilon_{A l} \sigma T_{1}^{4} A \cdot t \\
& Q_{\text {outrd } 2}=\varepsilon_{A l} \sigma T_{2}^{4} A \cdot t
\end{aligned}
$$

TPBD および Reference の対流熱伝達は，衝突流における 強制対流熱伝達と仮定し, 熱伝達率を式 (11) および式 (12) とする[9].

$$
\begin{aligned}
& \alpha_{1}=1.14 \sqrt{\frac{V_{f} d}{v_{1}}} \operatorname{Pr}_{1}^{0.4} \cdot \frac{\kappa_{1}}{d} \\
& \alpha_{2}=1.14 \sqrt{\frac{V_{f} d}{v_{2}}} \operatorname{Pr}_{2}^{0.4} \cdot \frac{\kappa_{2}}{d}
\end{aligned}
$$

式（7）から式（12）を式（6）に代入し, 白金抵抗温度セ ンサのサンプリング周期である 10 秒ごとの結晶構造の 変化による潜熱の式を式（13）に示す.
- Endoergic heat $\Delta$ Exoergic heat

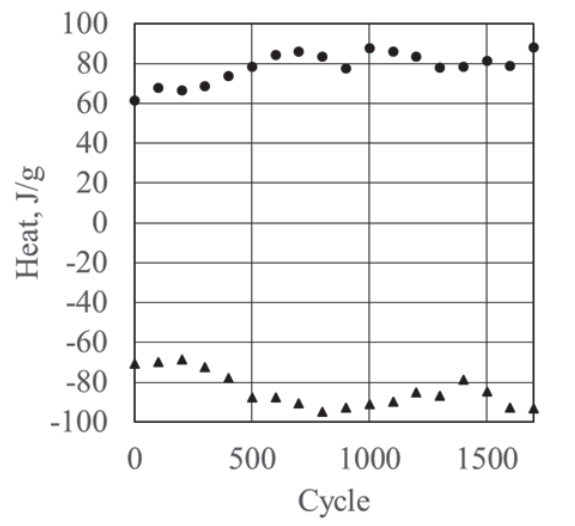

Fig. 9 Endoergic and exoergic heat from 1 to 1700 cycles

$$
\begin{aligned}
\mathrm{L} & =\mathrm{d} T_{2}\left(m_{A l 2} c_{A l}+m_{p t} c_{p t}\right)+\varepsilon_{A l} \sigma T_{2}^{4} A \cdot t \\
& +1.14 \sqrt{\frac{V_{f} d}{v_{1}}} \operatorname{Pr}_{1}^{0.4} \cdot \frac{\kappa_{1}}{d}\left(T_{f}-T_{1}\right) \cdot t \\
& -\mathrm{d} T_{1}\left(m_{A l 1} c_{A l}+m_{p t} c_{p t}+m_{H S T} c_{H S T}\right) \\
& -\varepsilon_{A l} \sigma T_{1}^{4} A \cdot t-1.14 \sqrt{\frac{V_{f} d}{v_{2}}} P r_{2}^{0.4} \cdot \frac{\kappa_{2}}{d}\left(T_{f}-T_{2}\right) \cdot t
\end{aligned}
$$

式（13）を用いて, 熱サイクル試験における蓄熱量および 放熱量の算出を行った. 算出に使用した温度履歴は, 図 8 の一点鎖線にて示した加熱時および冷却時の温度履歴で ある.一点鎖線にて示した温度範囲は TPBD と Reference の温度差が増大し始めてから最大となるまでの間の温度 履歴である. 1 サイクル目から 1700 サイクル目まで 100 サイクルごとに蓄熱量および放熱量の算出を行った結果 を図 9 に示す. 各サイクルにおける蓄熱量および放熱量 の比較を行った結果, 蓄熱量は $60 \mathrm{~J} / \mathrm{g}$ から $90 \mathrm{~J} / \mathrm{g}$ の間に, 放熱量は $-65 \mathrm{~J} / \mathrm{g}$ から-100 J/g の間の值になることが分っ た.これらの值の変動は蓄熱量と放熱量を見積もるため に使われている熱伝達の式(11)(12)中の $d$ に起因している と考えている. 蓄熱器と Reference は, 図 2 に示されてい るように, 棚からつるされており, 熱サイクル試験装置内 の気流によって回転する. 式中では一定值が与えている ため, 実験と異なり, 蓄熱量および放熱量が変動すると考 えている、いずれにしても, 蓄熱および放熱を繰り返すこ とによる蓄熱量および放熱量の減少の傾向は確認できな いことから, 1700 サイクルまでの蓄・放熱では, 蓄・放 熱量の劣化は発生しないと言える. 1700 サイクルは, 静 止軌道衛星の運用期間約 4 年半に相当する. 


\section{4. 結 論}

本研究では, 超小型人工衛星用蓄熱材料としてトラン ス-1,4-ポリブタジエン（TPBD）に注目し，蓄熱量と放熱 量をDSCによって測定した．さらに，同一サンプルに対 してラマン分光測定を用いて分子構造の測定を行った. また，熱サイクル試験を行い，繰り返し使用における TPBD の蓄熱と放熱時の温度履歴を取得した. 以上より, 下記の結論が得られた。

\section{TPBD の分子構造の変化と蓄熱量の関係}

ラマン分光法と DSC の測定結果を比較した結果, TPBD に含まれる- $\mathrm{CH}_{2}$ 内の $\mathrm{C}-\mathrm{H}$ 結合の自動酸化に起因した変化 が蓄熱量の劣化に影響を与えることが明らかとなった。

\section{2. 連続使用の中での TPBD の蓄熱性能の変化}

静止軌道衛星の約 4 年半の運用期間に相当する 1700 サ イクルの熱サイクル試験を行った．熱サイクル試験で測 定された温度履歴から, 熱サイクル試験中の TPBD の蓄 熱量と放熱量を算出した. 100 サイクルごとに蓄熱量と放 熱量を算出した結果, 蓄熱量は $60 \mathrm{~J} / \mathrm{g}$ から $90 \mathrm{~J} / \mathrm{g}$ の間に, 放熱量は-65 J/g から-100 J/g の間になることが分った。サ イクルごとに蓄熱量と放熱量を比較した結果, 両者に減 少の傾向は確認できなかった.

\section{[謝辞]}

本研究は，総合科学技術会議により制度設計された最 先端研究開発支援プログラムにより, 日本学術振興会を 通じて助成されたものです，北海道大学オープンファシ リティの顕微ラマンマイクロスコープシステムを使用し ました。記して，謝意を示します。

\section{NOMENCLATURE}

$A$ : Heat-transfer area, $\mathrm{m}^{2}$

$C_{A I} \quad:$ Specific heat of aluminum, $\mathrm{J} / \mathrm{gK}$

$c_{H S T}:$ Specific heat of Trans-1,4-Polybutadiene, $\mathrm{J} / \mathrm{gK}$

$c_{p t} \quad$ Specific heat of Platinum resistance thermometer, $\mathrm{J} / \mathrm{gK}$

$d \quad$ :Width of heat storage device and reference, $\mathrm{m}$

$d T$ :The amount of change in temperature, $\mathrm{K}$

$d U$ : Internal energy, $\mathrm{J}$

$L \quad$ : Latent heat of Cristal transition, $\mathrm{J}$

$m_{A l}$ :Mass of aluminum tape, $\mathrm{g}$

$m_{H S T}$ : Mass of test pieces, $\mathrm{g}$

$m_{p t} \quad$ : Mass of Platinum resistance thermometer, $\mathrm{g}$
Pr : Prandtl number of air

$Q_{c v}$ : Amount of heat transferred by convection, $\mathrm{J}$

$Q_{i n} \quad$ : Heat input, J

$Q_{\text {inrd }}$ : Heat input by radiation, $\mathrm{J}$

$Q_{\text {out }}$ : Heat dissipation, $\mathrm{J}$

$Q_{\text {outrd }}$ : Heat dissipation by radiation, $\mathrm{J}$

$t \quad$ : Sampling period, sec

$T \quad$ : Temperature, $\mathrm{K}$

Tf : Chamber temperature, $\mathrm{K}$

$V_{f} \quad$ : Flow rate in the chamber, $\mathrm{m} / \mathrm{sec}$

$\alpha \quad$ : Heat transfer coefficient, $\mathrm{W} / \mathrm{m}^{2} \mathrm{~K}$

$\mathcal{E}_{A l} \quad$ : Hemispherical emissivity of aluminum

$\kappa \quad$ : Thermal conductivity of air, $\mathrm{W} / \mathrm{mK}$

$v \quad:$ Kinetic viscosity of air, $\mathrm{m}^{2} / \mathrm{sec}$

$\sigma \quad$ : Stefan-Boltzmann constant, $\mathrm{W} \mathrm{m}^{-2} \mathrm{~K}^{-4}$

Subscripts

1 : Heat Storage Device

2 : Reference

\section{参考文献}

[1] L. Bledjian, D. V. Hale, M. J. Hoover, M. J. O'Neill; "Spacecraft Thermal Control Handbook", ed. D. G. Gilmore, Vol. 1 (2002) 373-403, The Aerospace Press, El Segundo.

[2] T. Totani, T. Kuni, T. Satoh, M. Wakita, H. Nagata; "Onorbit Test of Heat Storage Materials with Crystal Transformation", 45th International Conference on Environmental Systems, (2015) ICES-2015-085, Bellevue, Washington.

[3] 日本ゴム協会誌編集委員会 ; 「ゴムの劣化を理解し て防止する（その1）」，日本ゴム協会誌，77(2004) 109-115.

[4] 北野博巳, 功刀滋, 宮本真敏, 前田寧, 伊藤研策, 福 田光完; 「高分子の化学」 (2008), 三共出版株式会 社, 東京.

[5] 宇部興産株式会社 ; 「トランス-1,4-ポリブタジエン 組成物および蓄熱材料」(2000), 特開 2000-230103.

[6] 宇部興産株式会社 ; 「トランス-1,4-ポリブタジエン の分子量調節法」(2004), 特開 2004-346307.

[7] T. Totani, T. Kuni, T. Satoh, M. Wakita, H. Nagata; "Heat Storage Material with Crystal Transformation for Micro and Nano-satellites", 44th International Conference on Environmental Systems, (2014) 282-289, Tuscon, Arizona.

[8] 西岡利勝, 錦田晃一, 寺前紀夫 ; 「顕微赤外・顕微 ラマン分光法の基礎と応用」，(2008) 12-15, 技術情 報協会, 東京.

[9] 萩三二, 村上俊太郎; 「新版 熱伝達の基礎と演習」, (1975) 73, 東海大学出版会, 秦野.

[Received Mar. 26, 2015, Accepted Oct. 2, 2015] 